\title{
Uma filosofia inquietante da história: sobre Austerlitz, de W. G. Sebald*
}

An uncanny philosophy of history: W. G. Sebald's Austerlitz

\author{
Felipe Charbel \\ fcharbel@gmail.com \\ Professor Adjunto \\ Universidade Federal do Rio de Janeiro, Instituto de História \\ Largo de São Francisco de Paula, 1 - Centro \\ 22051-070 - Rio de Janeiro - Rio de Janeiro \\ Brasil
}

\section{Resumo}

O ensaio analisa o romance Austerlitz (2001), de W.G. Sebald, com o propósito de identificar os modos de figuração do tempo e da história na referida obra. Argumenta-se que Sebald, com a sua prosa de ritmo lento e caráter digressivo, um tanto antiquada na dicção e no tom narrativo, objetiva produzir efeitos de estranhamento que afetam os modos usuais de experiência do tempo dos leitores do romance. Argumenta-se ainda que as reflexões do personagem principal sobre a temporalidade moderna estão relacionados às considerações de Freud sobre o "inquietante", e que para Sebald a maneira apropriada de investigar essa dimensão insondável da historicidade seria por meio de uma "metafísica da história".

\section{Palavras-chave}

124 W. G. Sebald; Literatura; Historicidade.

\section{Abstract}

This essay examines W. G. Sebald's Austerlitz (2001), with the aim of identifying the modes of figuration of time and history in this novel. One argues that the features of Sebald's prose, such as the slowness, the frequent digressions, and the old-fashionedness of the diction and of the narrative tone, aim to produce effects of estrangement, affecting the ordinary modes of time experience which are common to the novel's readers. One also argues that the main character's thoughts about modern temporality are related to Freud's remarks on the "uncanny". In this sense, this essay points out that the "uncanny" is for Sebald an unfathomable characteristic of modern historicity, which can only be investigated by means of a "metaphysics of history".

\section{Keywords}

W. G. Sebald; Literature; Historicity.

Recebido em: 10/7/2015

Aprovado em: 7/12/2015

\footnotetext{
* Este ensaio é fruto de uma pesquisa financiada pelo Conselho Nacional de Desenvolvimento Científico e Tecnológico (CNPq) por meio da Bolsa de Produtividade em Pesquisa / Edital Ciências Humanas.
} 


\section{Os saberes da literatura}

A busca da verdade é sempre um ato de desespero. ${ }^{1}$

Das narrativas em prosa de W. G. Sebald, Austerlitz, publicada em 2001, é a que mais se volta para os problemas da história e do tempo. O romance retoma alguns dos temas habituais na poética de Sebald, como o lugar das coincidências e do acaso na vida cotidiana, as formas de eclosão do passado no presente, a melancolia do intelectual e do escritor, a flânerie urbana e as errâncias rurais, o comparecimento dos mortos entre os vivos, o trauma como condição insuperável da existência, o exílio e as ruínas, as formas perturbadoras de emergência da memória. No entanto, de maneira mais acentuada que em Vertigem (1990), Os emigrantes (1992) e Anéis de Saturno (1995), nota-se, em Austerlitz, uma cuidadosa articulação deste temário a um conjunto de observações sobre a temporalidade histórica, desdobradas, como conversa, nos encontros do narrador com o personagem Jacques Austerlitz.

É claro que não se trata de uma exposição sistemática de princípios Austerlitz é um romance, não um tratado filosófico. Mas as narrativas ficcionais afinadas com o seu tempo e com a evolução das formas literárias possuem, quase sempre, uma capacidade nada desprezível de articular conhecimentos diversos." "A literatura assume muitos saberes", disse Roland Barthes (2005, p. 18) em sua aula inaugural no Collège de France. Ela "trabalha nos interstícios da ciência", e está

sempre atrasada ou adiantada em relação a esta, semelhante à pedra de Bolonha, que irradia de noite o que aprovisionou durante o dia, e, por esse fulgor indireto, ilumina o novo dia que chega. A ciência é grosseira, a vida é sutil, e é para corrigir essa distância que a literatura nos importa (BARTHES 2005, p. 18).

Na coletânea de ensaios $A$ descrição da infelicidade (Die Beschreibung des Unglücks), publicada em 1985, Sebald exibe uma visão similar à de Barthes sobre a relação entre a literatura e as ciências. ${ }^{3}$ A literatura não pode ser vista, exclusivamente, como depositária de saberes diversos, postos em circulação pela ciência, embora essa dimensão não deva ser negligenciada. Os "conhecimentos psicológicos" da literatura, escreve Sebald (2005, p. 9), "são

\footnotetext{
${ }^{1}$ Passagem do ensaio "Quando a escuridão põe um ponto final. Sobre Thomas Bernhard". SEBALD 2005, p. 76. 2 O debate sobre o potencial cognitivo da literatura ganhou fôlego nas últimas décadas, com as contribuições de filósofos, críticos literários e historiadores como Jacques Bouveresse, Martha Nussbaum, Wayne Booth, Thomas Pavel, Dominick LaCapra, François Hartog e outros. Para Bouveresse (2008, p. 174), "as obras literárias dão uma contribuição importante ao conhecimento moral", não, porém, prescrevendo regras do bem agir ou fornecendo exemplos de orientação no mundo. Muito pelo contrário. O sentido prático da dimensão moral da literatura se voltaria para a exploração, numa espécie de "laboratório", das "realidades enigmáticas ou obscuras" da existência - zonas inacessíveis às ciências humanas, ou por elas desprezadas. Para um panorama da discussão, conferir a apresentação de Étienne Anheim e Antoine Lilti (2010) ao dossiê "Savoirs de la littérature", da revista Annales: Histoire, Sciences Sociales.

${ }^{3}$ A produção ensaística de Sebald é copiosa. Além de ter publicado diversos artigos em revistas especializadas e defendido uma tese sobre o escritor Alfred Döblin, ele organizou algumas coletâneas com os seus textos sobre literatura. Para uma análise da relação entre a produção ensaística de Sebald e a sua obra literária, conferir SWALES (2004).
} 
muitas vezes do mesmo valor, e em certas ocasiões superiores às percepções da psicoanálise". Escritores como Schnitzler e Hofmannsthal, por exemplo, oferecem, de acordo com Sebald, materiais de interesse considerável para a "investigação das formações e deformações psíquicas", cujo valor vai muito além do "meramente ilustrativo", uma vez que tais saberes contribuem para as gradações e diferenciações no âmbito dos "conhecimentos psicológicos, levemente condicionados pela tendência, tão caracteristicamente científica, ao doutrinário". ${ }^{4}$ A mesma lógica valeria para o conhecimento histórico. ${ }^{5}$ Ao tratar da "patografia do poder e da força" em Elias Canetti, Sebald (2005, p. 62) sugere que a historiografia, por sua atenção excessiva ao particular, é muitas vezes incapaz de compreender a amplitude de certos fenômenos históricos:

se a ciência histórica tende a neutralizar a demência convertida em história e a praticar o terror do poder no registro imparcial da res gestae, Canetti vê no que, por meio da força, se converte em história, uma forma exacerbada de expressão paranoica (SEBALD 2005, p. 62).

A imagem da historiografia, como apresentada por Sebald, é um tanto reducionista, mas isso não chega a prejudicar o seu argumento. É que mesmo os defensores mais aguerridos da racionalidade histórica concordam que a abordagem científica do passado, regradas por protocolos intersubjetivos de validação, não conseguem dar conta de certo conjunto de indagações. "Como ciência", afirma Jörn Rüsen (2001, p. 13), a história "não é a especialidade 126 competente para responder às perguntas fundamentais sobre o sentido e, no entanto, ela se sabe movida por tais questões". ${ }^{6}$ Deslocada do horizonte investigativo de uma ciência excessivamente fragmentada, exilada pelo declínio aparentemente irreversível das metanarrativas, a pergunta pelo sentido - histórico, temporal, mas também existencial - da "travessia terrena" encontra na literatura, especialmente nas narrativas ficcionais, um dos seus últimos refúgios. Nas palavras do escritor argentino Ernesto Sabato, "no mundo moderno, abandonado pela filosofia, fracionado por centenas de especializações científicas, o romance nos resta como o último observatório do qual se pode abraçar a vida humana como um todo" (apud KUNDERA 2006, p. 80).

\footnotetext{
${ }^{4}$ A literatura, diz Barthes (2005, p. 19), "engrena o saber no rolamento da reflexividade infinita: através da escritura, o saber reflete incessantemente sobre o saber, segundo um discurso que não é mais epistemológico mas dramático".

5 "Lembro-me dele dizendo em uma entrevista", escreve Charles Simic (2007, p. 149), "que há questões que não são permitidas a um historiador, pois elas são metafísicas. A verdade para ele sempre está em outro lugar, em algum lugar ainda não descoberto na miríade de detalhes esquecidos de uma existência individual". ${ }^{6}$ O que está em jogo, segundo Rüsen, é o caráter circular da matriz disciplinar da história. A ciência histórica se alimenta continuamente da vida prática - das carências de orientação no tempo próprias da historicidade -, e simultaneamente contribui para a transformação desse horizonte, conforme novas interpretações sobre os processos históricos são postas em circulação. Tanto a literatura como o cinema contribuem decisivamente para a movimentação desse círculo. É que, enquanto utilizam os discursos historiográficos, as artes desafiam esses discursos - mesmo sem colocá-los em xeque - , incorporando-os aos seus domínios e, principalmente, propondo investigações que a ciência não entende ser da sua competência abarcar. É o caso da recorrência, na literatura e no cinema - especialmente quando se voltam para temas históricos - , do que Frank Ankersmit (2005, p. 2) chamou de "fascínio contemporâneo pela (experiência do) evento". Há aí um paradoxo constitutivo, de enorme rendimento para as artes narrativas: por um lado, admite-se a irredutibilidade da experiência ao discurso, e ao mesmo tempo procura-se restituir, por meios diversos, algo da experiência direta do evento, da sua presença.
} 
Neste ensaio, discutirei as investigações realizadas por Jacques Austerlitz - e postas em enredo pelo narrador do romance - sobre o sentido histórico da sua própria existência. Inicialmente, comentarei as meditações do personagem, espalhadas aqui e ali pela superfície da narrativa, sobre as experiências do tempo e da história na modernidade. ${ }^{7}$ Mas não tratarei exclusivamente desses parênteses especulativos, de caráter abertamente programático. É que o deslocamento do conteúdo em relação à forma levaria a uma positivação de ideias que, a despeito da abrangência hermenêutica ou da densidade analítica, possuem, antes de tudo, uma função na economia narrativa. A relevância dos saberes da literatura passa menos pelo valor supostamente universal dos seus enunciados que por sua capacidade de estremecer os horizontes de expectativa de leitores e leitoras: a literatura, escreve Barthes (2005, p. 15), "encena a linguagem, em vez de, simplesmente, utilizá-la". Em Austerlitz, a prosa ralentada e digressiva, as longas frases entrecortadas por fotos perturbadoras, a acomodação dos pensamentos à diç̧ão melancólica e de sabor arcaizante, as frequentes coincidências e a sensação de inundamento do presente pelo passado - esses traços da poética de Sebald, tomados em conjunto, produzem uma atmosfera inquietante que nos leva a estranhar a nossa consciência histórica, e a considerar o que há de insondável na maneira como concebemos a condição temporal da existência.

\section{Passos perdidos}

Então ela disse, tão baixo que quase não se podia ouvi-la: What was it that so darkened our world? E Elias Ihe respondeu: I don't know, dear, I don't know (SEBALD 2008, p. 67).

Austerlitz é, das narrativas em prosa de Sebald, a que mais se aproxima da fisionomia tradicional de um romance. $\mathrm{E}$ a sua arquitetura é aparentemente simples: o narrador, que não chega a ser nomeado e carrega traços da biografia do autor, reproduz, numa espécie de testemunho secundário, suas conversas com o professor de história da arquitetura Jacques Austerlitz, a quem conhece, casualmente, na Salle des pas perdus de uma gare belga no ano de 1967, e com quem se encontrará, muitas vezes por coincidência, nos trinta anos seguintes. O local desse primeiro encontro não é destituído de força simbólica: a imagem dos "passos perdidos" antecipa as longas caminhadas em que Austerlitz esparramará, de forma digressiva e para deleite do interlocutor, sua erudição sobre os temas mais diversos, como a vida das mariposas e o estilo arquitetônico da era capitalista, batalhas napoleônicas e museus veterinários, fortificações medievais e a iluminação do McDonald's. Mas o "salão de passos perdidos" é também uma metáfora do fardo da história que, aos poucos, descobrimos ser um traço da sua personalidade - Austerlitz é um andarilho que não se

\footnotetext{
7 J. J. Long (2007) argumenta que a fortuna crítica de Sebald, voltada, predominantemente, para os tópicos do Holocausto, trauma e pós-memória, não prestou a devida atenção à maneira como esses e outros temas se articulam à consideração histórica do problema da modernidade.
} 
sente confortável em parte alguma, antes de tudo por não se sentir confortável consigo mesmo e com o próprio passado.

Os primeiros encontros de Austerlitz com o narrador obedecem a um regime de coincidências que flertaria com o inverossímil, não fosse a capacidade de Sebald de provocar, com o seu estilo deliberadamente anacrônico - uma espécie de "gótico contemporâneo, suavemente agitado e meditativo", nas palavras do crítico James Wood (2011, p. ix) - , sua capacidade de provocar, nos seus leitores, efeitos vividamente inquietantes. ${ }^{8}$ Penso aqui na definição de Freud (2010, p. 331) do inquietante, uma das suas aventuras mais bem-sucedidas no campo do pensamento estético: "aquela espécie de coisa assustadora que remonta ao que é há muito conhecido, ao bastante familiar". O sentimento inquietante, para Freud, pode ser disparado de diversas maneiras, como ao nos depararmos com a figura de um duplo, na antecipação involuntária de eventos futuros, no sentimento de retorno do mesmo (os déjà vus), nos acasos e coincidências, e na sensação de presença dos mortos. Estes tópicos são costumeiros na literatura de Sebald, e a relação com Freud não passou despercebida. Mark McCulloh (2003, p. 3), por exemplo, defende que, "a julgar pelas reações de críticos e leitores", muito do apelo da literatura de Sebald está relacionado à "restauração de um sentimento inquietante (assim como sublime) em relação à experiência cotidiana".

A onipresença de uma atmosfera inquietante na poética de Sebald prepara o terreno para o regime de casualidades que, em Austerlitz, mais que nas suas outras narrativas, põe a estória em andamento. Um segundo aspecto que 128 contribui para minimizar a desconfiança do leitor em relação aos encontros casuais de Austerlitz com o narrador é o fato de ambos serem apresentados como andarilhos inquietos, levados a explorar, num frenesi, tanto as principais cidades europeias como pequenos vilarejos, "em parte", como diz o narrador na abertura do romance, "por motivos de estudos, em parte por outras razões que a mim mesmo não me ficaram inteiramente claras" (2003 p. 7). ${ }^{9}$ Longe de se tratar de um detalhe pitoresco, a frequência anormal de encontros fortuitos nos quais Austerlitz, sem se espantar com o imprevisto e sem perder tempo com amenidades, vai direto ao ponto onde tinham interrompido a última conversa - , a incidência desses encontros fortuitos vai compondo, de forma gradual, um mosaico de coincidências cuja função simbólica é logo percebida: o que está em jogo é uma poética do acaso, em que a existência humana aparece impregnada, mas também regida, pelo aleatório e pelo acidental. ${ }^{10} \mathrm{E}$ isso não apenas no que diz respeito à vida de cada um dos personagens, considerados individualmente,

\footnotetext{
${ }^{8}$ Ainda segundo Wood (2010, p. 242-243), a "linguagem de Sebald é um edifício extraordinário e quase antiquário", e "apesar de toda a sua aparente quietude", seu princípio "é o exagero, um exagero que ele indubitavelmente aprendeu, em parte, com Thomas Bernhard". Mas enquanto "Bernhard exagera o grotesco", Sebald, "por contraste, exagera o elegíaco".

${ }^{9}$ Os narradores de Sebald são andarilhos que, normalmente, evitam os roteiros turísticos mais conhecidos (LONG 2010), e procuram, por meio da errância, entender os efeitos, tanto na natureza como na cultura, da destruição e das catástrofes (ARNDS 2010, p. 323). Para as apropriações feitas por Sebald da tradição literária das caminhadas, conferir MOSER (2010).

10 "Nós não somos apenas as nossas realizações", escreve o filósofo Odo Marquard (1991, p. 5), "mas também os nossos acidentes - nossos fatídicos acidentes. Ao que faço uma única qualificação adicional: nós somos mais os nossos acidentes que as nossas realizações. Portanto, temos de ser capazes de suportar o que é acidental, porque viver com o que é acidental [...] é a nossa condição historicamente normal". Agradeço a Sérgio da Mata pela recomendação de Marquard.
} 
mas também no que concerne à dinâmica da História: é como se o processo histórico, em alguma medida, fosse controlado por forças insondáveis que se fazem ver por meio dessas pegadas de casualidade. ${ }^{11}$

Não se trata, contudo, de uma filosofia da contingência, mas da figuração das casualidades como o aspecto visível da lógica, essencialmente obscura, da História. E tudo isso é apenas insinuado, por páginas e mais páginas, até que, já para o fim do romance, Austerlitz, após ser presenteado com uma foto da sua infância, dada como perdida, e relatar o sonho que, logo na sequência, teve com os seus pais biológicos, mortos há décadas, se põe a refletir sobre os mecanismos nebulosos que regem a eclosão das memórias represadas:

Não me parece, disse Austerlitz, que compreendamos as leis que governam o retorno do passado, mas sinto cada vez mais como se o tempo não existisse em absoluto, somente diversos espaços que se imbricam segundo uma estereometria superior, entre os quais os vivos e os mortos podem ir de lá para cá como bem quiserem e, quanto mais penso nisso, mais me parece que nós, que ainda vivemos, somos seres irreais aos olhos dos mortos e visíveis somente de vez em quando, em determinadas condições de luz e atmosfera (SEBALD 2008, p. 182, grifos meus).

Austerlitz pressente uma coerência, um sentido, uma "estereometria superior" nas formas eventuais de retorno do passado, que são como pequenos rasgos na tessitura da linearidade histórica, ilhas de simultaneidade onde os acontecimentos esquecidos e o instante dilatado coexistem em desarmonia. A noção de que essa estereometria possui a qualidade de ser "superior" talvez implique uma Providência ordenadora. De todo modo, é a dimensão de coextensividade entre o mundo dos vivos e o mundo dos mortos, independente das suas causas físicas ou metafísicas, o que chama a atenção na passagem, assim como a maneira como essa estereometria se manifesta na vida concreta: através dos detalhes. Se os mortos possuem um paradeiro efetivo - Hades, umbral, purgatório ou qualquer outro nome que o "país não descoberto"12 possa receber -, isso não é importante. Eles fizeram residência, desde sempre, na topografia da memória, individual e coletiva, e não deixam de emergir e de nos assombrar com a sua presença, em fotos antigas, em prédios abandonados, em

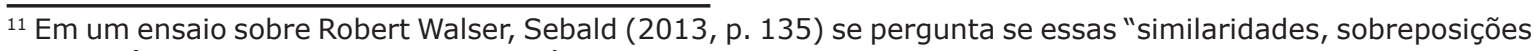
e coincidências" são "enigmas da memória, ilusões do eu e dos sentidos, ou então os esquemas e sintomas de uma ordem subjacente ao caos das relações humanas". Ele relata o seu espanto com uma série de coincidências ligando sua vida à do escritor suíço. Para começar, a semelhança física entre Walser e o avô de Sebald, e o fato de terem morrido no mesmo ano, 1956. Há também as similitudes literárias: a imagem da travessia do lago Constance ao luar, que aparece tanto em Der Räuber, de Walser (que Sebald só leu tardiamente), como em Os Emigrantes. Mas o que é verdadeiramente inquietante é o uso da palavra "Trauerlaufbahn", presente em Os Emigrantes e que Sebald imaginou ser um neologismo seu, em uma cena similar de Der Räuber, escrito décadas antes. A sensação que teve ao se deparar com essa passagem, escreve Sebald, foi a de que alguém, no "outro lado", estaria acenando para ele.

12 Um empréstimo de Hamlet, a expressão dá título a um ensaio sobre $O$ Castelo, de Kafka. O "país não descoberto", para Sebald (2005, p. 42-60), é a paisagem da morte. E K., o agrimensor - como Er na mitologia platônica - é um andarilho em tudo "semelhante às almas mortas para as quais nada é mais alheio que a sua própria história". O castelo é o "centro imaginário dessa comarca do outro lado", e o "enorme trabalho administrativo que ali se realiza", o "registro incalculável de todos os mortos" em todos os tempos. Os próprios ajudantes, essas "encarnações de antigas larvas", deixam a impressão de não estarem realmente vivos. E que todos sabem, "como reza a crença popular", escreve Sebald, que as hospedarias são lugares "onde os mortos se reúnem para uma última partida de cartas, antes de se dirigirem ao inferno". São o último destino de toda e qualquer viagem. "A vida e a morte não estão separadas nesse romance; uma é alegoria da outra".
} 
filmagens esquecidas. E o incômodo diante deles, para Austerlitz, é uma razão mais que suficiente para repensar o tempo histórico, ou mesmo para questionar a sua existência.

\section{Entropia histórica}

Que significado teria, perguntei comigo, o rio que não nasce de nenhuma fonte, que não deságua em nenhuma foz, que reflui constantemente sobre si próprio [...] (SEBALD 2008, p. 193).

Em ensaio sobre "a narrativa do trauma" em Sebald e em Coetzee, Dominick LaCapra (2013, p. 58) relaciona a melancolia dos narradores sebaldianos ao reconhecimento, que eles parecem possuir, de que o curso da história é entrópico. ${ }^{13}$ A ausência de sentido é experimentada não apenas como um traço das suas subjetividades, mas sobretudo como um aspecto constitutivo da condição histórica - como se a historicidade fosse uma contínua prestação de contas com o vazio da existência, e o trauma, mais que um "verossímil literário", efeito de real, fosse, na literatura de Sebald, a condição primeira da travessia terrena.

Em Austerlitz, a natureza constitutiva do trauma é ainda mais nítida que nas outras narrativas do autor. Cada qual à sua maneira, narrador e protagonista se veem engastados na História, de uma maneira que não apenas marca as suas sensibilidades, mas que vai se revelando, com o passar do tempo, um verdadeiro estorvo: o narrador, pela dificuldade de lidar com a "conspiração do silêncio" e com o peso de ter nascido na Alemanha na década de 1940, em um vilarejo onde muitos, de maneira mais ou menos ativa, colaboraram com os nazistas; ${ }^{14}$ Austerlitz, por ter sido afastado dos pais em 1939, antes de completar cinco anos, e enviado de Praga à Inglaterra num Kindertransport, e só recordar os acontecimentos da sua primeira infância muito tarde na vida, descobrindo, por exemplo, que seu idioma natal era o tcheco, não o inglês, e que

\footnotetext{
${ }^{13}$ A entropia história é apresentada, nos ensaios de Sebald, como "história natural da destruição", ideia que, segundo Andreas Huyssen (2003, p. 150), incorpora "elementos de uma metafísica tradicional da natureza", e os codifica "com a ajuda da imagem apocalíptica do anjo da história, de Walter Benjamin".

${ }^{14}$ Ao visitar a fortaleza de Breendonk, utilizada pelos nazistas como campo de prisioneiros, o narrador de Austerlitz nos revela, ao passar pela cantina onde os oficiais da SS faziam as suas refeições, que viveu, na juventude, entre pessoas como eles: "o que eu pude, sim, imaginar perfeitamente quando entrei afinal na fortaleza e olhei logo à direita [...] foram os pais de família e os filhos devotados de Vilsbiburg e Fuhlsbüttel, da Floresta Negra e da região de Münster, como eles se reuniam ali após o serviço para jogar baralho ou escrever cartas a suas amadas em casa, afinal de contas eu vivera entre eles até meus vinte anos" (SEBALD 2008, p. 27). Em uma entrevista, Sebald relata a incômoda proximidade com pessoas que colaboraram com os nazistas: "Meu pai esteve na campanha polonesa, e deve ter visto uma coisa ou duas... Sua unidade acampou nas florestas atrás da fronteira polonesa, talvez oito semanas antes de tudo começar. Tudo isso está nos nossos álbuns familiares. As primeiras fotos têm uma atmosfera de acampamento de escoteiros - eles estão sentados do lado de fora das suas tendas, consertando suas camisas, e na parte de baixo das fotos há legendas jocosas. 'Quem precisa de mulheres?' Então veio a ordem, e eles se moveram. E agora as fotos são de cidades polonesas, totalmente arrasadas, com apenas as chaminés deixadas de pé. Essas fotos me pareciam bem normais, quando eu era criança. Foi só mais tarde... Eu só vou para casa uma vez por ano, por dois dias, e eu olho para essas fotos, atualmente, e penso, 'Meu Deus, o que é isso?'". E então a entrevistadora pergunta: "Você consegue falar com os seus pais sobre isso?". E Sebald: "Na verdade, não. Embora meu pai ainda esteja vivo, com oitenta e cinco anos... São aqueles que têm uma consciência que morrem cedo, isso vai te triturando. Os apoiadores do fascismo vivem para sempre. Ou os resistentes passivos. Atualmente, na cabeça deles, é o que são. Eu sempre tento explicar aos meus pais que não existe diferença entre resistência passiva e colaboração passiva - é a mesma coisa. Mas isso eles não conseguem entender" (SCHWARTZ 2007, p. 67).
} 
os seus pais biológicos eram judeus, assassinados em campos de concentração. ${ }^{15}$ O modo como ambos prestam contas com o lançamento na História passa, simultaneamente, pelo reconhecimento da incapacidade de superar o passado e pela tentativa de conquistar alguma agência diante das forças impenetráveis do processo histórico: Austerlitz, perseguindo os rastros da sua vida pregressa; o narrador, se lançando à escrita.

O desejo de Austerlitz de conquistar alguma agência sobre a própria vida, após um colapso nervoso, o leva a uma investigação, não sistemática e de caráter digressivo, sobre a história, na tentativa de compreender o que ela significa, como ela é escrita e qual o seu sentido. Em uma passagem do romance, ao falar sobre a adolescência em um internato no País de Gales, onde foi criado pelos pais adotivos, Austerlitz se lembra das aulas de André Hilary, seu professor de história e dono de rara erudição sobre as guerras napoleônicas. "A pièce de résistance de Hilary", recorda Austerlitz, "era sem dúvida a batalha de Austerlitz". Capaz de descrever em minúcias a topografia do local, e de pintar um quadro bastante preciso da "disposição dos regimentos com os seus uniformes brancos e vermelhos, verdes e azuis, que no curso da batalha se mesclavam em combinações sempre novas, como cristais de vidro em um caleidoscópio", Hilary, que "podia falar durante horas sobre o 2 de dezembro de 1805" e mesmo assim "era da opinião de que abreviava em demasia todo o relato", se via obrigado a reconhecer, ao fim da sua exposição, que algo de essencial sempre escapava à narração histórica. "Todos nós", diz Austerlitz, "mesmo aqueles que pensam ter atentado para os menores detalhes, nos contentamos com recursos cênicos já levados ao palco por outros à exaustão". É que a história, para se apresentar como narrativa, precisa se valer de expedientes que acabam por afastá-la da vida:

Nós tentamos reproduzir a realidade, mas por mais que nos empenhemos, mais se impõem a nós as imagens batidas que compõem o espetáculo da história: o tamborileiro caído, o soldado de infantaria que acaba de apunhalar outro, o olho de um cavalo que salta da órbita, o imperador invulnerável cercado pelos seus generais, em meio ao turbilhão da batalha que se congela num átimo. Nossa relação com a história, esta era a tese de Hilary, era uma relação com imagens já predefinidas, impressas no recôndito dos nossos cérebros, imagens que continuamos a mirar enquanto a verdade reside em outra parte, em algum lugar remoto que ninguém ainda descobriu (SEBALD 2008, p. 74-75, grifos meus).

A verdade, para Austerlitz como para Hilary, não reside na historiografia. Naturalmente, não se trata, aqui, da verdade factual, da res gestae - expressão utilizada por Sebald no ensaio sobre Canetti —, mas da verdade existencial, com a sua incômoda fixação nos por quês. Ainda que estes sejam insondáveis, aos menos com os meios de que dispõem os historiadores e os filósofos, o significado particular da imersão de cada pessoa na História nunca deixa de se

\footnotetext{
15 O passado de Austerlitz só vem à tona quando uma série de casualidades, que funcionam como gatilhos para a emergência da memória reprimida, e que o levam a um espaço desativado da Liverpool Station, em Londres. Nessa ocasião, ele se recorda da sua chegada à cidade, e da recepção dos seus pais adotivos. Posteriormente, uma notícia no rádio sobre os Kindertransporten o faz ir a Praga, onde trava contato com Vera, uma vizinha e amiga de sua mãe que ajudou na sua criação, na década de 1930.
} 
abrir: "quando trago hoje à memória os relatos de André Hilary, disse Austerlitz, torno a lembrar da ideia que me surgiu então, de estar ligado de alguma forma misteriosa ao passado glorioso do povo francês". Esse sentimento, o vínculo enigmático e inquietante com a batalha que carrega o seu nome, é a maneira como o adolescente, que até então pensara se chamar Daffyd Elias e apenas algum tempo antes fora informado, pelo diretor do internato, Mr. Penrith-Smith, que deveria assinar as suas provas, por razões burocráticas, como Jacques Austerlitz - "it appears that this is your real name" - , essa é a maneira como o adolescente, despojado, num átimo, da própria identidade, redescreve a si mesmo: como alguém que possui, por razões que a ele não ficam inteiramente claras, um vínculo especial com a História. ${ }^{16}$

Se a historiografia, depreende Austerlitz nas suas investigações, possui uma inegável dimensão de ficcionalidade - os "recursos cênicos" e "imagens predefinidas", "levados ao palco por outros à exaustão" - , o tempo linear, o tempo contínuo, é uma das ferramentas mais notáveis da ficção histórica: "o tempo, disse Austerlitz no observatório astronômico de Greenwich, era de todas as nossas invenções de longe a mais artificial" (SEBALD 2008, p. 103). É que como estrutura a História é caótica, inapreensível, sem sentido, entrópica, e a sua engrenagem, se é que existe uma, se faz sentir apenas em flashes de coincidências e nas formas intempestivas de eclosão do passado. A pressuposição de uma lógica intrínseca ao processo histórico - a "estereometria superior" nada mais é que uma ficção de sentido, necessária à tentativa de autogoverno

132 que tanto Austerlitz como o narrador devem empreender para não sucumbir à melancolia.

\section{"Campo gravitacional das coisas esquecidas"}

Aliás, o que sabem os esquilos, e o que sabemos nós próprios, e como nos recordamos, e o que descobrimos no final? (SEBALD 2008, p. 200).

Já no primeiro encontro se define um pacto de escuta entre Austerlitz e o narrador, em que este assume a posição de ouvinte perfeito, sempre atento e com infinita curiosidade pelos pensamentos e divagações do seu interlocutor (e após um intervalo de duas décadas em que não se comunicam, pelo testemunho da sua história familiar). Essa escuta só é possível porque há uma convergência de sensibilidades entre eles. Tanto Austerlitz como o narrador possuem uma empatia desmesurada em relação à natureza, aos animais e aos seres humanos.

\footnotetext{
${ }^{16}$ A análise de James Wood (2001, p. xvii) do anúncio de Penrith-Smith merece ser reproduzida: "Jacques pergunta, com a polidez forçada do estudante inglês, 'Excuse me, sir, but what does it mean?' Ao que Mr. Penrith-Smith retruca: 'I think you will find it a small place in Moravia, site of a famous battle, you know'. E isso é tudo! E estamos em 1949. Jacques faz a pergunta que, possivelmente, poderia ser a pergunta de todo o romance, e o diretor apenas o remete à famosa batalha de 1805 entre os franceses e os austríacos. Considere tudo o que é omitido, ou reprimido, nessa resposta. O diretor poderia ter dito que Austerlitz é um nome judaico, e que Jacques é um refugiado dos nazistas. Ele poderia, com a ajuda da perícia de Mr. Hilary, ter acrescentado que Austerlitz, perto de Brno, no que então era a Tchecoslováquia, tivera uma próspera população judaica, e que talvez o nome de Jacques derivasse dessa comunidade. [...] Ele poderia ter acrescentado que os pais de Jacques dificilmente estariam vivos". "Mas Mr. Penrith-Smith não diz nada disso, e Jacques Austerlitz passará o restante do romance tentando encontrar as suas próprias respostas para as suas próprias perguntas".
} 
Sobretudo, é como se, mais que as outras pessoas, eles fossem capazes de assimilar a assiduidade dos mortos entre os vivos - não, porém, em suas existências fantasmáticas, mas como sujeitos históricos, presenças verdadeiras. Hiperaguçada pelo trauma, a empatia funciona como uma lente através da qual o passado se faz ver como força atuante no agora, contaminando o presente com a percepção, para eles ubíqua, de que cada milímetro do espaço físico reteve os flagelos, físicos ou morais, das pessoas ausentes. ${ }^{17} \mathrm{Um}$ exemplo dessa hipersensibilidade é o esquilo empalhado que, na ocasião de sua visita a Terezín, Austerlitz observa na vitrine de um bazar de antiguidades, onde provavelmente muitos dos artefatos em exposição pertenceram aos presos do gueto. Ao se deparar com o esquilo, Austerlitz é assaltado por uma compaixão tanto pelo ser vivo que foi como que congelado num instante que não se extingue, como pelo sofrimento dos prisioneiros, impregnado naquele objeto. ${ }^{18}$

Graças a essa sensibilidade extrema para captar as formas de eclosão do passado no presente, vai se desenhando, ao longo do romance, uma figuração bastante peculiar da experiência do tempo. Austerlitz e o narrador parecem presos ao agora, a um instante hipertrofiado em que se superpõem, caoticamente, várias camadas do passado. ${ }^{19}$ Há algo do paradoxo agostiniano aqui, o tempo entendido como distensão da alma e destituído de objetividade - um presente sempre inundado de memória e de devir. Mas, diferentemente do que se dá em Agostinho, a experiência do instante distendido tem um peso todo próprio; nas palavras de Austerlitz, um "campo gravitacional". Isso porque, no cronótopo do romance, tempo e espaço estão em desequilíbrio: inundado pelo tempo, o espaço se torna pesado e claustrofóbico, o sintoma de uma difusa doença da história. É o que se percebe na seguinte passagem, em que o protagonista comenta as suas andanças por Paris, à procura dos vestígios do pai desaparecido meio século antes:

Quando, por exemplo, nos meus caminhos pela cidade, olho para aqueles silenciosos pátios internos onde nada mudou durante séculos, sinto quase fisicamente como a corrente do tempo se retarda no campo gravitacional das coisas esquecidas. Todos os momentos da nossa vida me parecem então reunidos em um único espaço, como se os acontecimentos futuros já existissem e aguardassem apenas que chegássemos finalmente até eles, tal como nós, tendo aceitado um convite, chegamos a uma determinada casa a uma determinada hora. E não será possível imaginar, continuou Austerlitz, que também temos compromissos para cumprir no passado, no que já se foi e em grande parte está extinto, e lá temos de procurar lugares e pessoas que, quase além do tempo, guardam uma relação conosco? (SEBALD 2008, p. 250, grifos meus).

\footnotetext{
17 "Tal como as flores se voltam para o sol, assim também, por força de um heliotropismo secreto, o passado aspira a poder voltar-se para aquele sol que está a levantar-se no céu da história" (BENJAMIN 2012, p. 11).

18 Esse é o momento em que a sua língua natal, o tcheco, é recobrada, a começar por veverka, palavra que designa esquilo.

${ }_{19}$ François Hartog (2012, p. 76) associa a experiência do tempo em Austerlitz ao presentismo: "com W. G. Sebald, estamos também em um presente que dura ou que não passa, um tempo parado, produto também de uma catástrofe que ocorreu, mas que ele não conheceu diretamente". Hans Ulrich Gumbrecht (2010, p. 152), sem mencionar Sebald, fala em um "presente amplo", próprio da contemporaneidade, que "acabaria por acumular diferentes mundos passados e os seus artefatos numa esfera de simultaneidade".
} 
A metáfora do "campo gravitacional das coisas esquecidas" evoca duas qualidades do passado: sua força e o seu poder de atração. Podemos sentir essa energia gravitacional atuando em Austerlitz, e isso se deve, em grande medida, à impecável harmonização das fotos, modernas e antigas, à quietude agitada da prosa. O resultado é um efeito de suspensão: é como se, em vez de um rio caudaloso, o tempo fosse um lago de águas paradas, onde as imagens do passado vêm à tona e boiam a esmo. 20 "O desejo de suspender o tempo", escreve Sebald (2006, p. 145) em um ensaio sobre a poética de Nakokov, "só pode provar o seu valor na reevocação mais precisa das coisas há muito atingidas pelo esquecimento".

Em nenhum outro momento do romance esse efeito de suspensão é mais nítido que na narrativa sobre Llanwddyn, o vilarejo onde nasceu o pastor calvinista Emyr Elias, pai adotivo de Austerlitz. Numa das suas viagens dominicais, Elias estaciona a carroça às margens de uma barragem, conduz o jovem Daffyd (Jacques) até o centro do lago, e começa a falar sobre a casa do pai, "que estava lá embaixo a uma profundidade de cerca de trinta metros sob a água escura", e também sobre as outras casas que foram submersas "quando a barragem foi concluída, no outono de 1888". Muito impressionado, e com a mente transbordando de narrativas bíblicas, Daffyd enxerga em Elias "o único sobrevivente do dilúvio que dera cabo de Llanwddyn, ao passo que todos os outros, seus irmãos, seus parentes, os vizinhos e demais aldeões", na sua imaginação, ainda estariam "lá embaixo nas profundezas, onde continuavam a levar a vida sentados em casa ou andando pelas ruas, mas sem poder falar e de olhos esbugalhados". Austerlitz se recorda, então, do álbum de fotografias do pastor, com imagens "do seu lugarejo natal". "Eu não me cansava de olhar essas poucas fotos", diz ele, "até que as pessoas que me fitavam de dentro delas", principalmente "a garota sentada em uma cadeira no jardim com o seu cachorrinho no colo, tornaram-se tão familiares como se eu vivesse com elas no fundo do lago". E prossegue: "de noite, antes de ir para a cama no meu quarto gelado, eu sentia"... Mas a frase é interrompida pela exibição de uma foto, onde identificamos uma menina com um cachorrinho no colo, e é como se ela nos mirasse diretamente das profundezas do vilarejo submerso. O efeito é inquietante. ${ }^{21}$

Talvez por conta da "presunção de veracidade que", para Susan Sontag (2004, p 16), "confere autoridade, interesse e sedução a todas as fotos", o uso ficcional do retrato da menina, sua inclusão num "fingimento lúdico compartilhado"22, pode passar despercebido. Mas as imagens de Austerlitz, como sugere James Wood (2011, p. xiv), são aspectos de uma engrenagem

\footnotetext{
${ }^{20}$ Para Amir Eshel (2003, p. 74), a literatura de Sebald se destaca pela "poética da suspensão: uma poética que suspende noções como cronologia, sucessão, compreensão e encerramento", e que, "mais que descrever e comentar o evento histórico no tempo, constitui um evento, se torna a escrita de um tempo diferente, e literário". ${ }^{21} \mathrm{Na}$ preparação para a foto mais emblemática do livro, a do garotinho louro que representa Jacques aos quatro anos, Sebald (2008, p. 180) escreve: "a impressão que se tem, ela disse, é de que alguma coisa se agita dentro delas, como se ouvíssemos pequenos gemidos de desespero, gémissements de déspoir, foi o que ela disse, disse Austerlitz, como se as fotos tivessem memória própria e se lembrassem de nós, de como nós, os sobreviventes, e aqueles que já não estão entre nós, éramos então".

22 "Fingimento lúdico compartilhado" é como Jean-Marie Schaeffer (2010) define a ficção.
} 
muito complexa, e ficcional: "elas são fotografias de personagens inventadas" e, ao mesmo tempo, retratos "de pessoas reais que viveram uma vez mas que agora estão perdidas para a história". Para o leitor, não é relevante se a menina habitava ou não em Llanwddyn com o seu cachorrinho. O que nos comove é o fato de ela ter estado em algum lugar, em algum momento, e já não restar vestígios da sua existência. Olhamos para a foto e não vemos uma menina, mas um espectro, uma aparição proveniente da "terra não descoberta", simbolizando a nossa própria mortalidade. ${ }^{23}$

Ao jogar com a "presunção de veracidade" própria do registro fotográfico, Sebald cria um ruído no acordo tácito entre o autor e o leitor de ficção: o de que a literatura não aspiraria à verdade, uma vez que "as relações entre os textos literários e a realidade" seriam "meramente consequências de uma ilusão referencial" (PAVEL 1986, p. 6). Mas o emprego massivo de fotografias, em uma obra literária que trata de eventos históricos e comporta uma série de excursos sobre o tempo, acaba perturbando, de uma maneira quase intuitiva, esse horizonte antirreferencial: em parte, graças à instauração de uma semelhança fisionômica entre a ficção e a literatura documental, ou mesmo a historiografia, mas sobretudo pelo efeito de autenticidade que as fotos conferem ao texto, convidando o leitor a dar um novo giro no parafuso e a se voltar para a realidade. Essa alteração no modo como uma estória é contada e apreendida talvez seja o maior espólio, ainda não completamente assimilado, da literatura de Sebald. As fotos não estão ali para "ilustrar" o que quer que seja. ${ }^{24}$ Elas são aspectos da narrativa. Isoladas dos registros visuais, por exemplo, as meditações de Austerlitz sobre o tempo seriam provavelmente inócuas, ou no máximo apropriações criativas, e de rigor filosófico questionável, do pensamento histórico de Walter Benjamin. ${ }^{25}$ Somente como forma literária, no acontecer da literatura, essas meditações alcançam a sua máxima expressividade, sendo alimentadas pelo ritmo da prosa, pelo sabor das digressões, pelo tom melancólico da voz narrativa e, não menos importante, pela força metafórica das fotografias e dos outros registros visuais. E é através desse procedimento labiríntico que a literatura de Sebald reivindica para si tanto a incumbência de sondar o insondável, como a "impossível tarefa de encontrar a verdade". ${ }^{26}$

\footnotetext{
23 "Quer o sujeito tenha ou não morrido, toda fotografia é essa catástrofe", escreve Barthes (2011).

${ }^{24}$ Como sugere Mary Griffin Wilson (2013, p. 51), o uso das fotos, em Sebald, é frequentemente metafórico. Especialmente em Austerlitz, onde as imagens contribuem para a construção "do que Deleuze chamou de 'tempo não cronológico', em que várias 'regiões' do passado coexistem ao longo de um eixo vertical, mais que horizontal", resultando numa "espacialização do tempo". Para Antonio Marcos Pereira (2009), as imagens de Austerlitz "alteram a rota ordinária da leitura e perduram, com o magnetismo dos enigmas, nos fazendo retornar ao texto e às fotos com a pergunta 'Mas o que está acontecendo aqui ?". Para uma análise do procedimento de uso e seleção das imagens em Austerlitz, conferir POMPEU (2014).

${ }_{25}$ A influência de Benjamin é amplamente reconhecida, e se revela de várias maneiras: na ambição dos narradores sebaldianos de preservar algo do passado a despeito das forças destrutivas da História (MCCULLOH 2003, p. 55); na mobilização do conceito barroco de "história natural" (JACKMAN 2004); na relação entre o ato de narrar, a viagem e a morte (ZISSELSBERGER 2010, p. 11); na fixação com a figura do flâneur (LONG 2007, p. 6), dentre outros aspectos.

${ }^{26}$ A "impossível tarefa de encontrar a verdade", escreve Sebald (2005, p. 12) no prefácio de $A$ descrição da infelicidade, é um dos aspectos que contribuem para a "infelicidade do sujeito que escreve".
} 


\section{Metafísica da história}

[...] nas regiões mais altas o ar é menos denso, e o perigo de se precipitar-se, grande. ${ }^{27}$

Em Austerlitz, o caráter "antiquado da dicção e do tom narrativo"28 induz uma desaceleração do tempo. A morosidade no ritmo da leitura é assegurada não apenas pelo estilo - que evoca, como já foi amplamente notado, as poéticas de Adalbert Stifter e Thomas Bernhard ${ }^{29}$-, mas também pelas digressões que, fragmentando o continuum temporal, aguçam a percepção do leitor para os sinais da inundação do presente pelo passado. Juntamente com a poética do acaso, a abordagem digressiva e o ritmo vagaroso colaboram na composição de uma atmosfera algo onírica, caracterizada por uma sensação difusa de irrealidade e suspensão que, em contraste com a profusão de referenciais históricos, reforça o sentido de entropia. Ao mesmo tempo, essa atmosfera, em grande parte devedora de Kafka, prepara o terreno para a gravidade da matéria - como se a realidade fosse uma enorme distopia - , levando o leitor a intuir, gradativamente, que há algo de muito sério relacionado a Austerlitz.

Desde o início, a Grande História parece transbordar de Austerlitz através dos seus tiques (como o hábito de apertar o estojo de óculos a ponto de deixar ver "o branco dos nós dos dedos sob a pele"), fixações (por exemplo com estações de trem) e sintomas (as dificuldades na pronúncia do inglês, supostamente o seu idioma natal, e a recusa em escrever para o narrador quando este fixa um contínuo ajuste de foco, como se tateasse em busca de um ângulo apropriado à exposição das vicissitudes do seu interlocutor: nem tão próximo a ponto de se colocar no lugar dele, tentando reproduzir vicariamente o que ele sentiu, e nem tão distante a ponto de inviabilizar a empatia e a compaixão. "No campo da estética", escreve Sebald (2005, p. 173) em um ensaio sobre o escritor Joseph Roth, "há sempre, em definitivo, uma questão ética".

Essa preocupação com a abordagem do outro é uma marca do projeto estético de Sebald, e indicia uma ética da representação ficcional que se faz ver, nas suas entrevistas, pela profusão de comentários sobre as dificuldades de se apropriar, literariamente, das vivências de pessoas que efetivamente existiram:

[...] escrever sobre campos de concentração é, na minha opinião, praticamente impossível. Por isso você tem que encontrar maneiras de convencer o leitor de que isto é algo que está na sua cabeça mas que você não vai, necessariamente, introduzir em cada página. O leitor precisa ser

\footnotetext{
27 Passagem do ensaio "Para além da fronteira: A Repetição, de Peter Handke". SEBALD 2005, p. 210.

28 Termos de Sebald para descrever o próprio estilo. SCHWARTZ 2007, p. 86.

29 McCulloh (2003, p. 25) faz um inventário das principais influências literárias de Sebald: Borges, na dimensão documental e na representação do tempo; Kafka, na dicção e no clima; Nabokov e Stendhal, na "varredura autobiográfica"; além dos frequentemente mencionados Bernhard e Stifter. Para um estudo sistemático da leitura sebaldiana de Kafka, com foco em Vertigem, conferir MEDIN (2010). Para a leitura de Nabokov por Sebald, conferir KLEIN (2012).

30 Como percebe James Wood (2011, p. xix), à medida que avançamos no relato, "presente mas nunca dito, nunca escrito - e esse é o ato mais belo ato de contenção de Sebald -, está o outro nome histórico que sombreia o nome Austerlitz, o nome que começa e termina com as mesmas letras": Auschwitz.
} 
avisado que o narrador tem uma consciência, que ele está e talvez sempre tenha estado envolvido com essas questões. E é por essa razão que as principais cenas de horror nunca são abordadas diretamente. Eu acho que é suficiente lembrar as pessoas, porque todos nós vimos as imagens, mas essas imagens militam contra a nossa capacidade de pensamento discursivo, de refletir sobre essas coisas. E elas também paralisam, por assim dizer, a nossa capacidade moral. Daí que a única maneira de abordar essas questões seja, na minha opinião, obliquamente, tangencialmente, mais por referência que pela confrontação direta (SCHWARTZ 2007, p. 80).

Em Austerlitz, esse cuidado, diria mesmo esse escrúpulo, no tratamento do material histórico, se revela no minucioso trabalho de composição e de apresentação de um personagem que, embora fictício, combina aspectos das biografias de duas pessoas reais (SCHWARTZ 2007, p. 110-111). Essa aproximação cuidadosa nos prepara tanto para as singularidades quase idiossincráticas do personagem, como para as sutilezas do seu pensamento sobre o tempo e a história. É nesse contexto, no começo do romance, que o narrador se refere à "metafísica da história" de Austerlitz:

Desde o início me surpreendeu o modo como Austerlitz dava corpo a suas ideias no próprio ato de falar, como era capaz de desdobrar as frases mais harmoniosas a partir daquilo que lhe ocorria no momento, e como a transmissão de seu conhecimento através da fala constituía para ele a gradual aproximação a uma espécie de metafísica da história, na qual os fatos relembrados tornavam novamente à vida (SEBALD 2008, p. 16-17, grifos meus). ${ }^{31}$

O termo "metafísica da história" não é utilizado outra vez. Mas essa aparição solitária é, em si mesma, bastante eloquente. ${ }^{32} \mathrm{O}$ que está em jogo aqui é a própria visão do personagem sobre a história, uma visão que é inseparável do seu modo de ser, do seu estilo pessoal - sua voz, seus gestos, a sintaxe das suas frases, a penetração do seu discurso. É como se Austerlitz confirmasse a máxima de Buffon de que "o estilo é o próprio homem". George Steiner (2001, p. 46-47) escreve, em um famoso ensaio, que "quando lemos realmente, quando a experiência é a descoberta do significado, agimos como se o texto (a peça musical ou a obra de arte) encarnasse (esse conceito tem origem sacra) a presença real de um ente significante". A ideia de encarnação é, para mim, o punctum da passagem, por evocar um acontecimento, uma situação, uma ocorrência singular em que "conceito e forma constituem uma tautologia", coincidindo "ponto por ponto". Austerlitz, para o narrador, é a encarnação da História, a sua presença real. Na fala desse homem, nos diz o narrador, "os fatos

\footnotetext{
${ }^{31}$ Como as traduções para o português e para o inglês (que contou com a participação ativa de Sebald, inclusive reescrevendo diversas passagens) divergem nesse trecho, reproduzo aqui o original. "Es war Für mich von Anfang an erstaunlich, wie Austerlitz seine Gedanken beim Reden verfertigte, wie er sozusagen aus der Zerstreutheit heraus die ausgewogensten Sätze entwickeln konnte, und vie für ihn die erzählerische Vermittlung seiner Sachkenntinisse die schrittweise Annäherung an eine Art Metaphysik der Geschichte gewesen ist, in der das Enrinnerte noch einmal lebendig wurde". Agradeço a Pedro Caldas pelo auxílio na tradução e na interpretação da passagem.

32 Para Helen Finch (2007, p. 180), a metafísica da história "restaura a memória reprimida e aponta na direção de um nível esotérico" no relato sebaldiano da história. Amir Eshel (2003, p. 87) destaca os ecos de Marx, Adorno e Foucault, combinados numa espécie de "filosofia da histórica alegórica e sombria".
} 
relembrados tornavam novamente à vida", e isso é algo que o impressiona tanto ou mais que o conteúdo do seu testemunho. O que torna possível a encarnação, a re-encenação - ou reenactment, para falar como Collingwood - do passado no presente? Sebald não nos diz. Mas se a literatura possui algum dever, é o de explorar essas "regiões mais altas", onde "o ar é menos denso, e o perigo de precipitar-se, grande". E o instrumento disponível para esse alpinismo filosófico é a sondagem metafísica.

Embora o termo "metafísica" não seja frequente na literatura de Sebald, ele é rotineiro nos seus estudos sobre literatura. Sebald sugere (2005, p. 211), em um ensaio do final da década de 1980 sobre o romance $A$ Repetição, de Peter Handke, que já não existe, atualmente, um campo discursivo "em que a metafísica ainda possa reivindicar um lugar. E no entanto, a arte, onde e quando ela ocorra realmente, guarda a relação mais estreita com a esfera da metafísica". Essa é uma opinião que ele manteve até o fim da vida. Numa das suas últimas entrevistas, de março de 2001, Sebald faz um defesa da metafísica em termos semelhantes. Indagado sobre as conexões da sua obra com a poesia de Czesław Miłosz e Joseph Brodsky, Sebald diz que o que esses poetas "têm em comum é um interesse na metafísica". E vai além, afirmando que em escritores como Kafka e Dostoievski pode-se notar esse tipo de preocupação:

Eu acho que as melhores partes dos escritos de Dostoievski são as metafísicas, e não as religiosas. E a metafísica é algo que sempre me interessou, no sentido mesmo de especular sobre aquelas áreas que estão além do nosso conhecimento, por assim dizer. Sempre achei deplorável e, de certo modo, tolo, que os filósofos tenham decidido, em algum momento do século XIX, que a metafísica não era uma disciplina respeitável e que deveria ser lançada ao mar, e tenham se tornado lógicos e estatísticos. Isto me parecia uma dieta muito pobre (SCHWARTZ 2007, p. 115 , grifos meus).

"Especular sobre as áreas que estão além do nosso conhecimento": a "metafísica da história" nada mais é que a sondagem do que há de insondável na experiência da História. Ou mais precisamente: a investigação do modo inquietante como cada pessoa se vincula à História, e em certo sentido a encarna. Para Austerlitz, essa prestação de contas com a própria historicidade é terrivelmente perturbadora, e ganha corpo, no seu discurso, como uma filosofia inquietante da história, onde o presente e o passado coexistem como num conto de Borges, e as coincidências são marcas de uma ordem oculta que, como em Nabokov, se revela nos detalhes significantes e nos rasgos sutis na tessitura do real. Por um lado, essa filosofia inquietante da história, de caráter acentuadamente metafísico, só têm lugar na ficção: por meio dela prestamos contas, de forma especulativa, com a dimensão intangível da experiência histórica - especialmente se a História for entendida como desordem caótica e como trauma estrutural. Como ficção, a metafísica da história torna possível algum controle, alguma agência, sobre a vida, torna possível que não nos deixemos aprisionar pelo vazio da existência e pela melancolia. E ao mesmo tempo permite um vislumbre, que seja, sobre a totalidade do processo, sobre 
o significado de estar lançado na História. Mas a "metafísica da história" não é apenas isso, na poética de Sebald. Há toda uma dimensão da "presença real" do passado que uma visada especulativa procura, se não entender, ao menos trazer para o campo de percepção: o arrepio causado por uma foto antiga, o papel misterioso do acaso na existência cotidiana, o estranhamento de sentar em uma cadeira em que outros sentaram antes de nós, o sentimento de coabitação do espaço físico com os mortos.

\section{Referências bibliográficas}

ANHEIM, Étienne; LILTI, Antoine. Savoirs de la littérature. Annales. Histoire, Sciences Sociales, v. 65, n. 2, p. 253-260, 2010.

ANKERSMIT, Frank. Sublime Historical Experience. Stanford: Stanford University Press, 2005.

ARNDS, Peter. While the Hidden Horrors of History are Briefly Illuminated: The Poetics of Wandering in Austerlitz and Die Ringe des Saturn. In. ZISSElSBERGER, Markus (org.). The Undiscover'd Country. W. G.

Sebald and the Poetics of Travel. New York: Camden House, 2010.

BARTHES, Roland. Aula. Trad. Leyla Perrone-Moisés. São Paulo: Cultrix, 2005.

A câmara clara. Trad. Júlio Castañon Guimarães. Rio de Janeiro: Nova Fronteira, 2011.

BENJAMIN, Walter. Sobre o conceito de história. In: O anjo da história.

Trad. João Barrento. Belo Horizonte: Autêntica, 2012.

BOUVERESSE, Jacques. La connaissance de l'écrivain. Sur la littérature, la vérité \& la vie. Marseille: Agone, 2008.

ESHEL, Amir. Against the Power of Time: The Poetics of Suspension in W. G. Sebald's 'Austerlitz'. New German Critique, n. 88, p. 71-96, 2003.

FINCH, Helen. 'Die irdische Erfüllung': Peter Handke's Poetic Landscapes and W. G. Sebald's Metaphysics of History. In: FUCHS, Anne; LONG, J. J. (org.). W. G. Sebald and the Writing of History. Würzburg: Königshausen \& Neumann, 2007.

FREUD, Sigmund. O inquietante. In: Obras completas. Trad. Paulo César de Souza. São Paulo: Companhia das Letras, 2010. v. 14.

GUMBRECHT, Hans Ulrich. Produção de presença. O que o sentido não consegue

transmitir. Trad. Ana Isabel Soares. Contraponto: Ed. PUC-Rio, 2010.

HARTOG, François. Littérature et experiences contemporaines du temps. In: VIART, Dominique; DEMANZE, Laurent (org.). Fins de la literature. Historicté de la littérature contemporaine. Paris: Armand Colin, 2012.

HUYSSEN, Andreas. Rewritings and New Beginnings: W. G. Sebald and the Literature on the Air War. In: Present Past. Urban Palimpsests and the Politics of Memory. Stanford: Stanford University Press, 2003. 
JACKMAN, Graham. 'Gebranntes Kind?' W. G. Sebald's 'Metaphysik der Geschichte'. German Life \& Letters, v. 57, p. 456-471, 2004.

KLEIN, Kelvin Falcão. Entre vivos e mortos: imagem e memória. Revista eletrônica Literatura e Autoritarismo, v. 1, n. 19, 2012.

KUNDERA, Milan. A Cortina. Trad. Teresa Bulhões Carvalho da Fonseca. São Paulo: Cia das Letras, 2006.

LACAPRA, Dominick. History, Literature, Critical Theory. Ithaca and London: Cornell University Press, 2013.

LONG, J. J. W. G. Sebald. Image, Archive, Modernity. New York: Columbia University Press, 2007.

. W. G. Sebald: The Anti-Tourist. In. ZISSELSBERGER, Markus (org.). The Undiscover'd Country. W. G. Sebald and the Poetics of Travel. New York: Camden House, 2010.

MARQUARD, Odo. In Defense of the Accidental. Trad. Robert M. Wallace. New York, Oxford: Oxford University Press, 1991.

MCCULLOH, Mark. Understanding W. G. Sebald. Columbia: University of South Carolina Press, 2003.

MEDIN, Daniel. Three Sons. Franz Kafka and the Fiction of J. M. Coetzee, Philip Roth, and W. G. Sebald. Evanston: Northwestern University Press, 2010.

MOSER, Christian. Peripatetic Liminarity: Sebald and the Tradition of the Literary Walk. In. ZISSELSBERGER, Markus (org.). The Undiscover'd Country. W. G. Sebald and the Poetics of Travel. New York: Camden House, 2010.

PAVEL, Thomas. Fictional Worlds. Cambridge and London: Harvard University Press, 1986.

PEREIRA, Antonio Marcos. "Sebald explora fronteira entre ficção e memória". Jornal 0 Globo, 14 de fevereiro de 2009. Caderno Prosa e Verso.

POMPEU, Douglas Valeriano. Uma oficina poética de lembranças. Aletria, v. 24, n. 2, p. 77-94, 2014.

RÜSEN, Jörn. Razão histórica. Trad. Estevão de Rezende Martins. Brasília: Editora UnB, 2001.

SCHAEFFER, Jean-Marie. Why Fiction? Trad. Dorrit Cohn. Lincoln; London: University of Nebraska Press, 2010.

SCHWARTZ, Lynne Sharon (org.). The Emergence of Memory. Conversations with W. G. Sebald. New York, London, Melbourne and Toronto: Seven Stories Press, 2007.

SEBALD, W. G. Pútrida patria. Ensayos sobre literatura. Trad. Miguel Sáenz. Barcelona: Anagrama, 2005. 
Campo Santo. Trad. Anthea Bell. New York: The Modern Library, 2006. Austerlitz. Trad. José Marcos Macedo. São Paulo: Companhia das Letras, 2008.

. Austerlitz. Trad. Anthea Bell. New York: Modern Library, 2011.

A Place in the Country. Trad. Jo Catling. New York: Random House, 2013.

SIMIC, Charles. "Conspiracy of Silence". In. SCHWARTZ, Lynne Sharon (org.). The Emergence of Memory. Conversations with W. G. Sebald. New York; London; Melbourne; Toronto: Seven Stories Press, 2007.

SONTAG, Susan. Sobre fotografia. Trad. Rubens Figueiredo. São Paulo: Companhia das Letras, 2004.

STEINER, George. Presenças verdadeiras. In: Nenhuma paixão desperdiçada. Trad. Maria Alice Máximo. Rio de Janeiro: Record, 2001.

SWALES, Martin. Theoretical Reflections on the Work of W. G. Sebald. In. LONG, J. J.; WHITEHEAD, Anne (org.). W. G. Sebald - A Critical Companion. Seattle: University of Washington Press, 2004.

WILSON, Mary Griffin. Sheets of Past: Reading the Image in W. G. Sebald's Austerlitz. Contemporary Literature, v. 54, n. 1, p. 49-76, 2013.

WOOD, James. W. G. Sebald's Uncertainty. In: The Broken Estate.

Essays on Literature and Belief. New York: Picador, 2010. Introduction. In: SEBALD, W. G. Austerlitz. Trad. Anthea Bell. New York: Modern Library, 2011.

ZISSELSBERGER, Markus. Introduction: Fluchtträume / Traumfluchten. Journeys to the Undiscover'd Country. In: ZISSELSBERGER, Markus (org.). The Undiscover'd Country. W. G. Sebald and the Poetics of Travel. New York: Camden House, 2010. 